merits and many advantages. The illustrations, which are generally good, demonstrate the excellent preservation of morphological detail and other characteristics of smears in a comprehensive range of tumours and other types of lesion encountered in a neurosurgical practice. Incorporated in the introductory chapter there is an excellent two-page tabulation of tumours of the central nervous system, based on the current W.H.O. classification.

Early chapters describe the technique, emphasizing its simplicity and describe smear preparations of normal brain and of typical reactive changes. Resembling an atlas, the major part of the volume is devoted to illustrations (in black and white) with commendably short descriptive paragraphs. Six of the fourteen chapters are arranged systematically in the order of the classification provided and are devoted to tumours. Lesions compressing the spinal cord are dealt with in one chapter and lesions other than tumours - encephalitis, cerebral infarction and lesions in bone-in another.

One hopes that the prospective user of this book will not be discouraged by the authors' evident aim to include almost every lesion that may be encountered in a neurosurgeon's career, but will concentrate on the chapters which deal with the most common entities.

The simplicity of the smear technique has been emphasized but many pitfalls in the interpretation of the preparations may be encountered even by an experienced neuropathologist and the trainee will be well advised to give early attention to Chapter 14 which is entitled 'Diagnostic Problems'. In this chapter valuable information and guidance in handling these problems is provided.

PAUline KaHN

Whittington Hospital. London $\mathrm{N} 19$

\section{Clinical Aspects of Renal Physiology}

By G. R. D. Catto and J. A. R.Smith. Pp. 147, illustrated. Baillière Tindall, London, 1981. £7.50.

During the last few years there has been a steady output of middle of the road nephrology books, reflecting the greater interest in this speciality than has even been manifested before. This is a healthy sign and, obviously, writing books of this sort is something to be encouraged.

I was therefore interested to see a book on Clinical Aspects of Renal Physiology, and I think the authors have managed successfully to combine clinical advice on a background of physiological information. The problem in this sort of exercise is, of course, that if physiology is presented in the same sort of detail as is common in nephrology journals, virtually nobody would read the book, but I do feel that the authors have, perhaps, gone too far in the opposite direction as, for example, persistently referring to salt when what is meant is sodium.

The book is too short to be of much value to Membership students, but I would recommend it to medical students as being easily readable and readily understood. The diagrams are plain, but I was not particularly impressed by the quality of the photographs, and I was disappointed by the rather superficial treatment of important new ideas like natriuretic hormone.

However, these reservations will not, I am sure, detract from its value at the level of the final year student or house staff, as an introduction to the fascinating and intricate mystery of renal physiology.

\section{Department of Nephrology and} The Royal Free Hospital, London NW3

\section{An Introduction to Paediatric Neurology}

By Gwilym Hosking. Pp. 352, illustrated. Faber and Faber, London, 1982. $£ 11.50$ (cased) $£ 5.95$ (paperback).

This compact paperback volume is aimed primarily at nurses and professions supplementary to medicine, social workers, teachers of handicapped children and others involved in their care. It is concise and readable and covers most of the important neurological $\varrho$ disorders in childhood. It also has a useful chapter of line drawings of anatomical structure of the nervous system and a further chapter $\propto$ of illustrations of the common as well as more specialized procedures $c$ in neurological investigation. The descriptions on the whole are clear, concise and comprehensible and dogmatic enough to give an air of authority. In a few places more basic description might be helpful-for example in the section on ataxia Dr Hosking wades in directly to a discussion of the various mechanisms and causes, $\frac{\sigma}{\bar{n}}$ without giving a clear description of what ataxia really is or looks $\frac{\bar{W}}{\frac{D}{\sigma}}$ like. Each chapter has a useful short list of recommended further $\mathbb{D}$ reading and at the end there are also some general texts for reference and a very useful list of charitable and other organizations that may $\omega$ be of help in relation to the management of individual disorders. The $\overrightarrow{-}$ role of the parent in the management of children with handicaps is ? also outlined. This book could also provide a useful base-line in $\vec{A}$ paediatric neurology for the undergraduate medical student, but will $\omega$ probably not have sufficient depth to interest the postgraduate.

V. DUBOwITZ

Royal Postgraduate Medical School,

London W12

\section{MCQs in Paediatrics}

By W. S. UtTley. Pp. xii +168 . Churchill Livingstone, Edin- 을 burgh, 1982. £3.95.

The reviewer must confess that his first encounter with the multiple choice question some years ago produced a rather unfavourable $\vec{O}$ reaction-a mixture of scepticism and hostility towards its contradictory mixture of dogmatism and imprecision. This first reaction has slowly changed, mainly as a result of increasing experiences $\vec{f}$ MCQs as an examiner for the DCH and of composing them for the examination and various publications. There is no doubt also thert $N$ the standard of MCQs is rising all the time, and has now reached the position where the MCQ mark tallies very well with the marks awarded by examiners in an essay paper in the same examination. Although not yet universally beloved of candidates, there are many $\bar{O}$ reasons for their popularity with examiners. They do not allow of verbosity, they eliminate the horror of indecipherable handwriting $\mathbb{D}$ and they greatly reduce (though they do not abolish) the disadvantage of sketchy knowledge of the language. Above all, they save a huge amount of time-they can be marked by a computer.

This small book is based on Forfar's excellent Textbook of $\vec{P}$ Paediatrics, and the author has clearly set out to acquaint prospective examinees with the format of these questions and his answers to them. In a useful preamble, he discusses the construction of different $\bar{\partial}$ types of MCQ, the qualities needed by an ideal question, how to 3 answer them and how to analyse their success in terms of ease of $\bar{\partial}$ answering, discrimination between the good and bad examinee, and 3 correlation with the rest of the examination. This is a very valuable $i$ section and should not be missed either by candidates or examiners. The lay-out is convenient with the answers on the reverse side of every page, making it very easy to cross-check. The answers are $ᄋ$ accompanied by short and pertinent comments on the topic justifying the 'true' or 'false' label.

As far as the questions themselves are concerned, they range from the commonplace to the highly esoteric, and the reviewer must $\mathrm{N}$ express a personal dislike for a key which consists of a long $\sigma$ paragraph, almost a clinical history. This seems to be a departure $N$ from the true nature of the genuine $\mathrm{MCQ}$-pithy and to the $\mathrm{N}$ point-and seems to offer opportunities for clouding the issue. It $\omega$ would also hardly be expected that the reviewer would agree with every answer and with every comment on the reverse page. But these 0 are minor quibbles and do not amount to a significant criticism of this book. The author does not say whether he personally composed $\mathbb{E}$ every question in the book. If he did, and knowing the labour : involved in formulating them, he is to be congratulated indeed.

Any prospective candidate who works through this book withou 